\section{Effect of position and typeface variation on perceptual clarity ${ }^{1}$}

RALPH NORMAN HABER, LIONEL $S T A N D I N G,{ }^{2}$ and JUDITH BOSS, ${ }^{3}$ University of Rochester, Rochester, N.Y. 14627

To determine if $S$ 's ability to perceive and to recognize a letter would increase with well spaced repetitions, even if the position and/or the typeface changed from flash to flash, four Ss were shown six flashes of single letters and were asked to guess the letter and to indicate whether or not they saw it clearly. Recognition (measured by both forced-choice guesses and by perceptual reports) increased at a constant rate whether an identical test letter was flashed on each trial or the form and/or position of the letter was varied (over four levels each) between flashes. The mean level of recognition was also unimpaired by variations in typeface and/or position, when measured by forced-choice guesses. With a perceptual report, recognition was lowered by variation of the test stimulus, apparently through a change in report criterion. These data suggest that the perceptual repetition effect must operate through arousal of the letter name or some other representation of the stimulus rather than by a simple sensory facilitation.

Studies by Haber and his co-workers have shown that tachistoscopic recognition of verbal material is increased substantially by repetitions of the stimulus or by providing prior knowledge of the stimulus (e.g., Haber, 1965; Haber \& Hershenson, 1965; Haber \& Hillman, 1966; Hershenson, 1969; Standing, Sales, \& Haber, 1968; see Haber, 1969, in press, for brief reviews). Ine repetition etfect occurs whether a judgment of clarity or a recognition response is the dependent variable, and appears to be truly perceptual rather than a problem-solving process.

The present experiment examined whether or not the repetition effect was dependent upon the formal identity of successive repetitions of each stimulus. Would clarity and recognition still improve if each flash of a letter varied in iypeface or in position? If they do, the effect is unlikely to be due to a simple sensory enhancement, but rather must result from some type of mediational process, such as is preditable from Haber's (1967, in press) extension of Hebb's (1949) model of the growth of a cell assembly. A sensory effect is unlikely for other reasons, especially since the interval between successive flashes can be as long as $10 \mathrm{sec}$ without impairing the growth of clarity (Standing, Sales, \& Haber, 1968).

\section{SUBJECTS}

Four students, with normal or corrected vision, served as paid Ss. The Ss were unaware of any experimental hypothesis. APPARATUS AND STIMULI

A two-channel tachistoscope (Scientific Prototype, Model 800 F) was used, with test and adapting fields set at $2.0 \mathrm{~mL}$. The test stimulus was a single letter, selected randomly from the set $\mathrm{A}$ through $\mathbf{L}$. It was presented $1 \mathrm{deg} 50 \mathrm{~min}$ away from the fixation point, at one corner of an imaginary upright square centered on the fixation point. The letter, printed in black on white by the Letraset process, appeared in one of four forms: upper-case Univers 55, 18-point; lower-case Univers 55, 24-point; upper-case Helvetica Light Italic, 18-point; or lower-case Helvetica Light Italic, 24-point. These different forms of test letter were equal in vertical visual angle (22 $\mathrm{min}$ ), and thickness of component lines $(0.9 \mathrm{~mm})$. The stimuli were viewed at a distance of $80 \mathrm{~cm}$ in a dark room; each presentation was initiated by $\mathrm{S}$, using a microswitch. To provide a fixation region (15 min wide), the central portion was omitted from an upright black cross in the background field. The latter field was illuminated at all times except during viewing of the test field.

\section{PROCEDURE}

Each $S$ was practiced for about $1 \mathrm{~h}$ before testing commenced. He was then tested under the four experimental conditions: no stimulus variation, typeface variation, position variation, and typeface and position variation. The conditions were given in an order determined by a Latin square. Two consecutive testing sessions were given under each condition, with sessions separated by a day or more. Thus, each $S$ served in eight sessions plus practice.

Each session commenced with measurement of S's daily threshold, defined as the stimulus duration yielding a .5 probability of correct forced-choice response under the no-variation condition. A staircase method was used with steps of. $.5 \mathrm{msec}$. Thresholds averaged about $5 \mathrm{msec}$.

Sixteen test letters were then shown during the session, each selected randomly from the 10 possible letters (except that a given letter never appeared more than three times per session). Each test letter was flashed six times by $S$, at the threshold duration, with approximately $6 \mathrm{sec}$ between flashes. Under the no-variation condition, the 16 trials comprised one letter for each of the four-position by four-typeface combinations. The $S$ was informed in advance of the combination used, and each test letter was then flashed six times without any stimulus variation. Under the other three conditions, the typeface and/or position of the test letter varied randomly between each of the six flashes; the nonvarying factor was given in blocks of four letters each.

As a check on S's fixation, a small black dot appeared on $50 \%$ of the flashes of each trial (selected randomly) in the fixation region of the visual field corresponding to the imaginary intersection of the fixation cross. This dot was about $90 \%$ visible when fixated correctly, but was invisible if $S$ fixated the regions of the field where the test letter appeared.

The Ss were instructed to fixate carefully upon the center of the fixation cross and to press the switch when ready. They were then told to make three responses after every flash: a forced-choice identification of the letter (guessing if necessary) from the specified set, a "dot"/"no dot" response, and a perceptual report of whether the letter was clearly perceived or not on that flash ("seen"/"guessed"). Thus, a typical response sequence might be " $G$, no dot, seen." The $S$ was told that each letter would be presented for six flashes, and he was fully instructed concerning the nature of the four experimental conditions and the sequence in which he would receive them.

\section{RESULTS}

Forced-choice and perceptual-report performance under the four conditions is shown in Fig. 1. The total number of correct responses for the forced-choice task (upper four functions in Fig. 1) did not differ significantly between the four experimental conditions $(F=1.61$, $\mathrm{df}=3 / 129, \mathrm{p}>.05)$, between $\mathrm{Ss}(\mathrm{F}=2.79$, $\mathrm{df}=3 / 6, \mathrm{p}>.05)$, or between days of testing $(F<1)$. The probability of correct response increased significantly over the six repetition flashes $(F=11.37$, $d f=5 / 129$, $\mathrm{p}<.01)$. This trend did not interact with conditions $(F<1)$.

The frequency with which $S$ gave a perceptual report of seeing the letter (middle four functions of Fig. 1) also increased over the repetition flashes $(F=16.1, \mathrm{df}=5 / 129, \mathrm{p}<.01)$, although the level of performance was much lower than for the forced-choice task. Reliable differences were also found between $S s$ $(F=11.3, \quad d f=3 / 6, \quad p<.01)$ but not between days $(\mathrm{F}<1)$. 


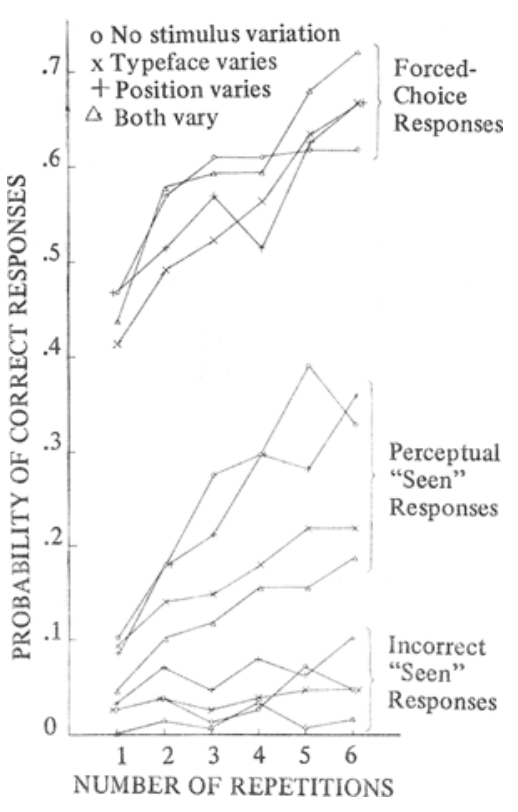

Fig. 1. Probability of correct forced-choice discrimination of the test letter, probability of $S$ reporting that he has seen the test letter, and probability of reporting "seen" on a trial where an incorrect forced-choice identification of the letter has been made, on each of six repeated flashes, for four $S s$ combined.

The frequency of total perceptual reports differed between the conditions $(\mathrm{F}=17.2$, df $=3 / 129, \mathrm{p}<.01)$. Applying Duncan's multiple range test (with $\alpha=.01$ ), recognition under the no-variation condition was significantly higher than under the typeface or the typeface- and position-variation conditions. No interaction was found, however, between conditions and rate of increase $(F=1.0)$.

The frequency with which a perceptual report was given on trials where the forced-choice response was incorrect (lower four functions of Fig. 1) was low under all conditions (approximately $3 \%$ ). Even so, it increased significantly over trials $(F=2.68, d f=5 / 129, p<.05)$ and differed between conditions $(F=10.0$, $\mathrm{df}=3 / 129, \mathrm{p}<.01)$. Duncan's multiple range test (with $\alpha=.01$ ) showed that this frequency was reliably lower under the typeface- and position-variation condition than under the other three. Again, no interaction between trials and conditions was found $(F<1)$. Reliable differences between Ss were found for incorrect free-response frequency $(F=45.5$, df $=3 / 191, p<.01)$.

The data were also analyzed for differences in correct response (forced-choice), between the four stimulus typefaces and the four positions, using the observations collected under the no-variation condition. No significant effects were found between the typefaces $(\mathrm{F}=1)$, the positions $(\mathrm{F}=1.3, \mathrm{~d} f=3 / 27$, $\mathrm{p}>.05)$ or their interaction $(F=1.84$, $\mathrm{df}=9 / 27, \mathrm{p}>.05$ ).

The frequency of incorrect response in the dot-detection task was unaffected by any experimental factor except Ss $(\mathrm{F}=7.81, \mathrm{df}=3 / 129, \mathrm{p}<.01)$, the range being $11 \%-20 \%$ errors.

\section{DISCUSSION}

The results show that the perceptual repetition effect is not dependent upon repeated exposures of an unchanging single stimulus, since it occurs equally well when the form or the position of the stimulus changes between exposures. Thus, it is some feature of the letter's identity, rather than its specific physical form and location, that must be carried over from one flash to the next to enhance S's recognition performance. The results thus confirm and extend those of Standing \& DaPolito (1968), who found that a repetition effect occurred for test items (three-letter sequences) that were repeated at varying positions on each flash within a nine-letter array. The experiment also shows that the repetition effect occurs with peripheral vision. Further, the finding that even on the first flash a stimulus is still identified equally well (with a forced-choice or a perceptual report) when it appears at a known or an unknown location within the visual field is in agreement with the results of Grindley \& Townsend (1968).

The substantial differences between the forced-choice and perceptual-report accuracies obviously reflect the advantage $S$ takes of spatial cues in making forced-choice responses. No differences are found among the conditions with forced choice, while the variable conditions did result in lower accuracies when S. made a perceptual report. That this is due to variation in S's criterion for report is suggested by the relationship between correct and incorrect perceptual-report accuracies. Not surprisingly, Ss become more cautious when both position and typeface varies between flashes.

The present findings are taken as evidence that the repetition effect represents a mediated process rather than improvement in a simple sensory discrimination with repeated flashes (a distinction also noted by Green \& Swets, 1966). That a capital A can facilitate perception of a subsequent lower-case italic A stimulus in a different part of the visual field means that the repetition effect must be operative through a generalized process associated with the perception of ' $A$ ' stimuli. These results are consistent with Haber's (in press) assumption that stimulus clarity and recognizability are a function of the degree of arousal of a cell assembly-like central representation. With familiar stimuli, for which such assemblies have been previously organized, arousal should be a function of stimulus variables (contrast, energy, etc.), prearousal, selective sets, and repetition. These results now show, with respect to this model, that arousal of an assembly need not be dependent upon any specific stimulus parameters, such as retinal location, typeface, or probably even size of print, since the assembly represents the name or the concept of the letter and is not unique to each version of the letter.

\section{REFERENCES}

GREEN, D. M., \& SWETS, J. A. Signal detection theory and psychophysics. New York: Wiley, 1966. Pp. 257-258.

GRINDLEY, G. C., \& TOWNSEND, V. Voluntary attention in peripheral vision and its effects on acuity and differential thresholds. Quarterly Journal of Experimental Psychology, 1968, 20, 11-19.

HABER, R. N. Effect of prior knowledge of the stimulus on word-recognition processes. Journal of Experimental Psychology; 1965, 69, 282-286.

HABER, R. N. Repetition as a determinant of perceptual recognition processes. In $\mathrm{W}$. Wather-Dunn (Ed.), Symposium on models for the perception of speech and visual form. Cambridge: M.I.T. Press, 1967. Pp. 202-212. HABER, R. N. Repetition, visual persistence, visual noise, and information processing. In $\mathrm{K}$. N. Leibovic (Ed.), Information processing in the nervous system. Columbus: Springer, in press.

HABER, R. N., \& HERSHENSON, M. Effects of repeated brief exposures in the growth of a percept. Journal of Experimental Psychology, $1965,69,40-46$.

HABER, R. N., \& HILlMAN, E. R. Changes in single letter clarity with repetition. Perception \& Psychophysics, 1966, 1, 347-350.

HEBS, D. O. The organization of behaviour. New York: Wiley, 1949.

HERSHENSON, M. Stimulus structure, cognitive structure, and the perception of letter arrays. Journal of Experimental Psychology, 1969, 79, 327-335.

PAIVIO, A. Mental imagery in associative learning and memory. Psychological Review, in press.

STANDING, L. G., \& DaPOLITO, F. Limitations of the repetition effect revealed by partial report. Psychonomic Science, 1968, 13, 297-298.

STANDING, L. G., SALES, B. D., \& HABER, R. $\mathrm{N}$. Repetition versus luminance as a determinant of recognition. Canadian Journal of Psychology, 1968, 22, 442-448.

\section{NOTES}

1. This research was supported by Grants MH 10753 (Public Health Service) and GB 5910 (National Science Foundation) to the first author. The authors gratefully acknowledge the careful work of Iris Blumenkrantz in collecting and scoring data, and of James Pomerantz in obtaining pilot data.

2. Now at Bishop's University, Lennoxville, Quebec, Canada.

3. Now at Dalhousie University, Halifax, Nova Scotia, Canada. 